\title{
Metabolic syndrome among 13 year old adolescents: prevalence and risk factors
}

\author{
AA Fadzlina', Fatimah Harun', MY Nurul Haniza², Nabilla Al Sadat', Liam Murray ${ }^{3}$, Marie M Cantwell ${ }^{3}$, Tin Tin Su², \\ Hazreen Abdul Majid ${ }^{2}$, Muhammad Yazid Jalaludin ${ }^{1 *}$
}

From International Research Symposium on Population Health 2013

Kuala Lumpur, Malaysia. 18-22 November 2013

\begin{abstract}
Background: Obesity and metabolic syndrome is prevalent among Malaysian adolescents and has been associated with certain behavioural factors such as duration of sleep, screen time and physical activity. The aim of the study is to report the prevalence of overweight/obesity, metabolic syndrome and its risk factors among adolescents.

Methods: A multi-staged cluster sampling method was used to select participants from urban and rural schools in Selangor, Perak and Wilayah Persekutuan Kuala Lumpur. Participants underwent anthropometric measurement and physical examination including blood pressure measurement. Blood samples were taken for fasting glucose and lipids and participants answered a self-administered questionnaire. Overweight and obesity was defined using the extrapolated adult body mass index (BMI) cut-offs of $>25 \mathrm{~kg} / \mathrm{m}^{2}$ and $>30 \mathrm{~kg} / \mathrm{m}^{2}$, according to the International Obesity Task Force (IOTF) criteria. Metabolic syndrome was defined based on International Diabetes Federation (IDF) 2007 criteria.
\end{abstract}

Results: Data were collected from 1361 participants. After excluding incomplete data and missing values for the variables, we analysed a sample of 1014 participants. Prevalence of overweight and obesity in this population was $25.4 \%(\mathrm{~N}=258)$. The prevalence of metabolic syndrome was $2.6 \%$ in the population and $10 \%$ among the overweight and obese adolescents. Participants who slept between 7 and 9 hours a day has a lower risk of developing metabolic syndrome OR 0.38(0.15-0.94).

Conclusion: Our results provide the prevalence of metabolic syndrome in Malaysian adolescents. Adequate sleep between 7 and 9 hours per day reduces the risk of developing metabolic syndrome.

\section{Introduction}

The International Obesity Task Force (IOTF) in the year 2000, established the definition of overweight and obesity in childhood, based on pooled international data for body mass index (BMI) linked to the adult overweight and obesity cut-off of $25 \mathrm{~kg} / \mathrm{m}^{2}$ and $30 \mathrm{~kg} / \mathrm{m}^{2}$ respectively [1]. Over the recent years, the prevalence of childhood obesity has increased rapidly worldwide [2]. In Malaysia, the prevalence of overweight and obesity in children and adults has followed a similar trend [3-5]. With the growing obesity epidemic within the adolescent population, this has

\footnotetext{
* Correspondence: yazidj@ummc.edu.my

'Department of Paediatrics, Faculty of Medicine, University Malaya, Malaysia Full list of author information is available at the end of the article led to the increasing frequency of metabolic syndrome within this population [6,7].

Metabolic syndrome is an interrelated cluster of conditions including visceral adiposity, dyslipidaemia, hypertension and hyperglycaemia. Reaven and his colleagues [8] first described metabolic syndrome in 1988. However, prior to 2007, there was no uniform or standard criteria to diagnose metabolic syndrome in children and adolescents. A few definitions of metabolic syndrome that has been adapted for use in children and adolescents includes the National Cholesterol Education Program Adult Treatment Panel III (ATP III) [9], American Association of Clinical Endocrinologists (AACE) [10], World Health Organization (WHO) [11,12] and European Group for the Study of Insulin resistance (EGIR) [13]. Due to the differences in its 
definition, International Diabetes Federation (IDF) consensus was developed in 2007 to define metabolic syndrome in children and adolescents [14]. The IDF definition is divided into age groups due to the age related differences in blood pressure, lipid levels, and body size in children and adolescents [14]. As there was insufficient data available in younger children, the definition of metabolic syndrome is only applicable in children of 10 years of age and older. Metabolic syndrome was defined as the presence of, abdominal obesity and 2 or more of these criterias (elevated triglycerides, low level of high density lipoprotein-cholesterol, high blood pressure and high fasting plasma glucose). With this new definition, few studies have reported the prevalence of metabolic syndrome in their population [7,15-17].

Previous studies had shown associations between certain behavioral characteristics and obesity as well as metabolic syndrome. For example, short sleep duration has been associated with overweight, obesity and metabolic risk factor [18-20]. A study by Chen et al. has shown that adequate sleep is associated with good health status and adoption of health-related behavior [21]. Prolonged screen time $[22,23]$ and physical inactivity $[24,25]$ however had been identified to be inversely related to metabolic syndrome and its risk factors. These two factors may impose a major problem to the country as it has been recently found that about $64 \%$ of Malaysian adolescents are physically inactive [26].

Data regarding the prevalence of metabolic syndrome amongst Malaysian adolescents and their behavioral characteristics is still lacking. Realizing the importance of such data and the health implications, a population based study was conducted to determine the prevalence of obesity, and metabolic syndrome and its risk factors among Malaysian adolescents.

\section{Methodology}

\section{Ethics statement}

The study received ethical approval from the Medical Ethics Committee, University Malaya Medical Centre (IRB Refence number 896.34)

\section{Study design}

This study was done in conjunction with the Malaysian Health and Adolescents Longitudinal Research Study (MyHeARTs), an on-going prospective longitudinal cohort study on risk factors for chronic non-communicable diseases among adolescents. The details of the study has been described previously [27].

This study was conducted in three states in the northern and central zone of Peninsular Malaysia - Perak, Selangor and Wilayah Persekutuan Kuala Lumpur. Participants comprised of both male and female students, aged 13 years old, who were in their first year of the public secondary school (Form 1) and able to read and understand the national language of Malaysia, which is Bahasa Melayu. Participants from boarding, religious and vernacular schools were excluded from the study as they were not representative of the majority of students in Malaysian schools. The total sample size calculated for this study was 1500 , using the formula $n=\left(z^{2} \cdot p \cdot q / r \cdot e^{2}\right) x D e f f$, whereby $p$ (prevalence) as 33\% using the estimated prevalence of smoking among adolescents in Malaysia from the Global Youth Tobacco Survey (GYTS) in 2003, and $r$ (response rate) of $50 \%$ based from the MyHeARTs feasibility study conducted in October to November 2011. As our study is mainly looking at prevalence of metabolic syndrome in the population, the sample size needed for our study using the above formula, is 330 based on the metabolic syndrome prevalence (4.6\%) in our neighbouring country [24].

The sampling of the study was done using a multistaged cluster sampling design. A complete list of secondary schools in Perak (238 schools), Selangor (261 schools) and Wilayah Persekutuan Kuala Lumpur (96 schools) was obtained from the Department of Education of Malaysia, and the list was used as a sampling frame. 15 schools were randomly selected as a cluster from the computergenerated random number lists to ensure randomization. Eight schools were from urban area whereas 7 schools were from rural area. Subsequently, all Form 1 students (age 13 years old) who fulfilled inclusion criteria were invited to participate in the study. Consent form for parents, ascent agreement for participants and detailed infromation sheets about the study were distributed to them. Participants were students who attended school on the day of the data collection and handed in the agreed consent form and ascent forms. Students without parental consent and individual agreement were excluded from the study. All participations were voluntary.

\section{Questionnaire, anthropometic measurement and physical examination}

Participants were asked to fill a standardized pre-tested questionnaire under the supervision of trained enumerators. The questionnaire collected information on the participants socio-demographic details such as date of birth, age, gender and ethnic group and daily activities such as duration of sleep and screen time. To minimize the variability in measurements, the research team members attended a special workshop where appropriate training was provided for standardization of measurement. Body weight was measured in light clothing without shoes and socks using a calibrated digital electronic weighing scale (Seca 813, Seca, UK) recorded to the nearest 0.1 kilogram. Height was measured using a calibrated vertical stadiometer (Seca Portable 217 Seca, UK) recorded to the nearest 0.1 centimetre. Body mass index (BMI) was calculated using weight $(\mathrm{kg})$ divided by the square of height 
$\left(\mathrm{m}^{2}\right)$ and expressed as $\mathrm{kg} / \mathrm{m}^{2}$. Waist circumference was measured using ergonomic circumference measuring tape (Seca 201, Seca, UK), measured at the midpoint between the lowest rib margin and the iliac crest and recorded in the nearest 0.1 centimetre. Blood pressure was measured using mercurial sphygmomanometer (Spirit CK-101C, Spirit Medical Co., Taiwan) and stethoscope after a 5 minutes rest, in a seated position with the right upper arm positioned at the heart level and the feet flat on the ground [28]. Body fat percentage was measured using a portable Body Composition Analyzer (Tanita SC-240, Tanita, Japan) and expressed by percentage (\%).

\section{Biochemical analysis}

Venous blood samples were taken after an overnight fast for at least ten hours prior to the study visit. Blood samples were collected by a trained phlebotomist and medical officers. Approximately $2 \mathrm{mls}$ of blood was collected into sodium fluoride test tube for the measurement of fasting blood glucose. Another approximately $3 \mathrm{mls}$ blood sample was collected in a plain test tube for the measurement of fasting lipids (triglyceride, total cholesterol, high density lipoprotein-cholesterol (HDL-C) and low density lipoprotein cholesterol (LDL-C). All blood samples were properly labelled and transported to a private certified central laboratory for analysis.

\section{Definitions}

Overweight and obesity was defined using the IOTF criteria with extrapolation to adult BMI cut-offs of $25 \mathrm{~kg} / \mathrm{m}^{2}$ for overweight $\left(21.91 \mathrm{~kg} / \mathrm{m}^{2}\right.$ for males and $22.58 \mathrm{~kg} / \mathrm{m}^{2}$ for female) and $30 \mathrm{~kg} / \mathrm{m}^{2}$ for obesity $\left(26.84 \mathrm{~kg} / \mathrm{m}^{2}\right.$ for male and $27.76 \mathrm{~kg} / \mathrm{m}^{2}$ for female) [1]. Central obesity was defined by waist circumference $\geq 90$ th percentile according to waist circumference percentile curves for Malaysian children and adolescents [29]. The cut-off value used was $83.8 \mathrm{~cm}$ for male and $78.8 \mathrm{~cm}$ for female [29]. Metabolic syndrome and its risk factors were determined based on the International Diabetes Federation (IDF) 2007 definition of metabolic syndrome [14]. Participants were diagnosed with metabolic syndrome if they had central obesity (waist circumference $\geq 90$ th percentile) plus at least 2 of the following criteria: (1) triglycerides $\geq 1.7 \mathrm{mmol} / \mathrm{l}$, (2) HDL-cholesterol $<1.03 \mathrm{mmol} / \mathrm{l}$, (3) systolic blood pressure $\geq 130 \mathrm{mmHg}$ or diastolic blood presure $\geq 85 \mathrm{mmHg}$, (4) fasting plasma glucose $\geq 5.6 \mathrm{mmol} / \mathrm{l}$ or known type 2 diabetes mellitus [14].

\section{Statistical analysis}

All participants' demographic information, anthropometric measurements and laboratory results were entered and analyzed using SPSS Software Version 19. Only completed data were analyzed. The comparison of socio-demographic data with IOTF BMI and metabolic syndrome were obtained using descriptive statistics. Independent $\mathrm{t}$-tests were used to compare mean values of metabolic syndrome risk factors by gender. Independent $\mathrm{t}$-tests were also used to compare participants' school location and risk factors for metabolic syndrome. One-way ANOVA was used to determine the difference in means between ethnic groups and each risk factors for metabolic syndrome while logistic regression was used to determine the association between sleep duration and metabolic syndrome.

\section{Results}

Data was collected from 1361 participants who volunteered to be in the study. After excluding incomplete data and missing values for the variables, the total number of participants eligible for analysis was 1014. The sociodemographic characteristics of the participants are shown in Table 1 . The majority were female, $61.8 \%(\mathrm{~N}=627)$ while males comprised $38.2 \%(\mathrm{~N}=387)$. Among the ethnic groups, Malays constituted the majority, $83.6 \%$ $(\mathrm{N}=848)$, followed by Chinese $8.8 \%(\mathrm{~N}=89)$, Indian $4.8 \%$ $(\mathrm{N}=49)$ and other ethnic groups $2.8 \%(\mathrm{~N}=28)$. Students from urban $(53.7 \%, \mathrm{~N}=545)$ and rural locations $(46.9 \%$, $\mathrm{N}=463$ ) were equally represented. The prevalence of overweight and obesity in this population was $25.4 \%$ $(\mathrm{N}=258)$, whereby $16.0 \%(\mathrm{~N}=162)$ were overweight and 9.4\% $(\mathrm{N}=96)$ were obese.

Each metabolic risk factor among the non-obese, and the overweight and obese group was studied and the results are shown in Table 2. The overweight and obese group showed a much higher percentage of each individual metabolic risk factors compared to the non-obese. The major difference was seen in waist circumference, 65.12\% (CI 59.26-70.97) of overweight and obese group had waist circumference $\geq 90$ th percentile in comparison to $0.93 \%$ (CI $0.24-1.61$ ) in the non-obese group.

Table 3 shows the individual risk factors of metabolic syndrome among the overweight and obese participants. Overweight and obese participants with metabolic syndrome had statistically significant higher mean waist circumference, systolic and diastolic blood pressure and triglyceride levels, and lower HDL-cholesterol levels. Fasting blood glucose was also found to be higher in the metabolic syndrome group. However, the result was not statistically significant.

The prevalence of metabolic syndrome in this population was $2.6 \%$, as shown in Table 4 . The prevalence was higher among males, $3.4 \%(n=13)$ compared to females, $2.1 \%(\mathrm{n}=13)$. There was no difference in the prevalence of metabolic syndrome in rural versus urban areas. Among the overweight and obese participants, the prevalence of metabolic syndrome was $10.0 \%(\mathrm{n}=26)$. Overweight and obese males had higher percentage of metabolic syndrome, $11.9 \%(\mathrm{n}=13)$ compared to females, $8.7 \%(\mathrm{n}=13)$. 
Table 1 Socio-demographic characteristics between non-obese and overweight/obese group $(\mathbf{N}=1014)$

\begin{tabular}{llll}
\hline & $\begin{array}{l}\text { Non-obese }(\mathbf{N}=\mathbf{7 5 6}) \\
\text { Mean (SD) or Percentage (\%) }\end{array}$ & $\begin{array}{l}\text { Overweight/Obese }(\mathbf{N}=\mathbf{2 5 8}) \\
\text { Mean (SD) or percentage (\%) }\end{array}$ & $\begin{array}{l}\text { Total }(\mathbf{N}=\mathbf{1 0 1 4}) \\
\text { Mean (SD) or percentage (\%) }\end{array}$ \\
\hline Total & $74.6 \%$ & $25.4 \%$ & $100 \%$ \\
Age & $12.87 \pm 0.32$ & $12.88 \pm 0.36$ & $12.88 \pm 0.33$ \\
Gender & & & \\
Male & $36.7 \%$ & $42.2 \%$ & $38.2 \%$ \\
Female & $63.2 \%$ & $57.8 \%$ & $61.8 \%$ \\
Ethnicity & & & \\
Malay & $83.9 \%$ & $82.6 \%$ & $83.6 \%$ \\
Chinese & $8.1 \%$ & $10.9 \%$ & $8.8 \%$ \\
Indian & $5.0 \%$ & $4.3 \%$ & $4.8 \%$ \\
Others & $2.9 \%$ & $2.3 \%$ & $2.8 \%$ \\
Location & & & \\
Urban & $52.7 \%$ & $56.6 \%$ & $53.7 \%$ \\
Rural & $47.2 \%$ & $43.4 \%$ & $46.3 \%$ \\
\hline
\end{tabular}

Table 2 Comparison of risk factors for metabolic syndrome among non-obese and overweight/obese participants

\begin{tabular}{lll}
\hline Risk factors & $\begin{array}{l}\text { Non-obese }(\mathbf{N}=\mathbf{7 5 6}) \\
\text { \% }(\mathbf{C l})\end{array}$ & $\begin{array}{l}\text { Overweight/Obese }(\mathbf{N}=\mathbf{2 5 8}) \\
\text { \% }(\mathbf{C l})\end{array}$ \\
\hline Waist circumference $(\geq 90$ th percentile) & $0.93(0.24-1.61)$ & $65.12(59.26-70.97)$ \\
Systolic BP $(\geq 130 \mathrm{mmHg})$ & $1.19(0.42-1.97)$ & $13.95(9.7-18.21)$ \\
Diastolic BP $(\geq 85 \mathrm{mmHg})$ & $3.17(1.92-4.43)$ & $10.07(6.38-13.78)$ \\
Triglyceride $(\geq 1.7 \mathrm{mmo} / \mathrm{l})$ & $3.57(2.25-4.90)$ & $15.50(11.06-19.95)$ \\
$\mathrm{HDL}-$ cholesterol $(<1.03 \mathrm{mmol} / \mathrm{l})$ & $3.04(1.82-4.27)$ & $15.89(11.4-20.38)$ \\
Fasting glucose $(\geq 5.6 \mathrm{mmol} / \mathrm{l})$ & $3.17(1.92-4.43)$ & $4.26(1.78-6.75)$ \\
\hline
\end{tabular}

BP: Blood pressure, HDL-Cholesterol: High Density Lipoprotein-Cholesterol

Table 3 Risk factors of metabolic syndrome among the overweight/obese group

\begin{tabular}{llll}
\hline Risk factors & Metabolic syndrome & No metabolic syndrome & p-value \\
\hline Waist circumference $(\mathrm{cm})$ & $93.21 \pm 8.07$ & $84.19 \pm 9.21$ & $\mathrm{p}<0.001$ \\
Systolic BP $(\mathrm{mmHg})$ & $123.31 \pm 11.82$ & $115.75 \pm 11.93$ & $\mathrm{p}=0.002$ \\
Diastolic BP $(\mathrm{mmHg})$ & $78.92 \pm 9.96$ & $72.79 \pm 9.18$ & $\mathrm{p}=0.002$ \\
Triglyceride $(\mathrm{mmol} / \mathrm{l})$ & $2.07 \pm 0.72$ & $1.07 \pm 0.44$ & $\mathrm{p}<0.001$ \\
$\mathrm{HDL}$-cholesterol $(\mathrm{mmol} / \mathrm{l})$ & $1.09 \pm 0.28$ & $1.33 \pm 0.25$ & $\mathrm{p}<0.001$ \\
Fasting glucose $(\mathrm{mmol} / \mathrm{l})$ & $5.31 \pm 1.33$ & $4.85 \pm 0.39$ & $\mathrm{p}=0.086$ \\
\hline
\end{tabular}

BP: Blood pressure, HDL-Cholesterol: High Density Lipoprotein-Cholesterol

Table 5 shows that participants who slept between 7 and 9 hours a day had a lower risk of developing metabolic syndrome, OR $0.38(0.15-0.94)$. This factor was found to be independently associated with metabolic syndrome after controlling for screen time and physical activity. Analysis was also carried out for the association between screen time and physical activity with metabolic syndrome but no significant associations were found (results not shown).

\section{Discussion}

This research studied the 13 years old adolescents attending the public schools in both rural and urban areas in Malaysia. The majority of the students were of
Malay ethnicity followed by Chinese and Indians reflecting the ethnic population of the country [30]. The majority of the participants in this study were females, by voluntary enrolment, although the gender of the students in each state were equally distributed [31].

This study revealed that the prevalence of overweight and obesity was high at $25.4 \%$ whereby $16.0 \%$ were overweight and $9.4 \%$ obese. A study by Ismail et al. had shown an increase in the prevalence of overweight and obesity in Malaysian children from $20.7 \%$ in 2002 to $26.5 \%$ in 2008 [3], whereas a recent study by Wee et al. showed a higher prevalence of $34.2 \%$ [5]. Compared to their Asian counterparts, the prevalence of overweight and obesity of the adolescents in this study is much higher than in the 
Table 4 Prevalence of metabolic syndrome among all participants $(\mathrm{N}=1014)$ and among the overweight/obese group $(\mathrm{N}=\mathbf{2 5 8})$

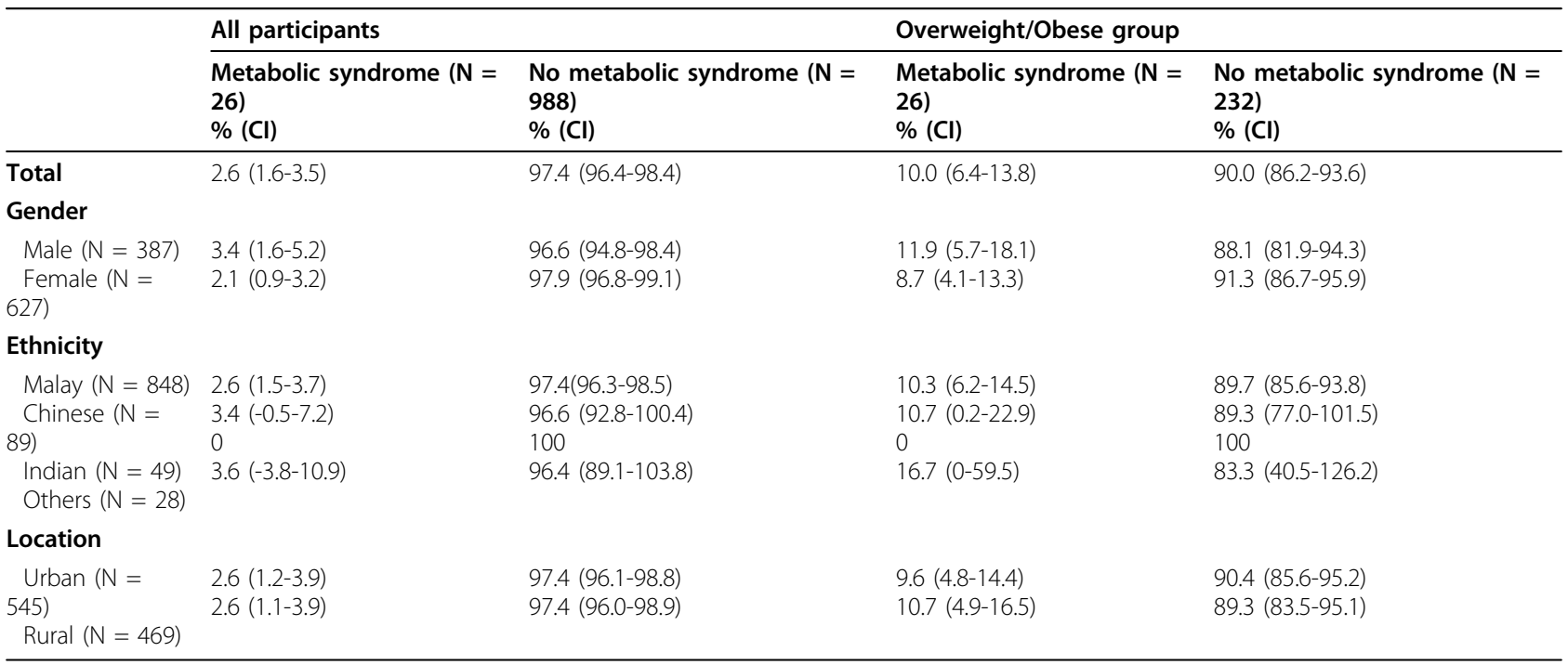

Table 5 Odds ratio for metabolic syndrome based on sleeping time

\begin{tabular}{llll}
\hline Average sleep duration/day & Unadjusted model & Intermediate model & Fully adjusted model \\
\hline$<7$ hours & $0.52(0.16-1.71)$ & $0.52(0.16-1.17)$ & $0.52(0.16-1.76)$ \\
$7-9$ hours & $0.38(0.15-0.93)^{*}$ & $0.38(0.16-0.95)^{*}$ & $0.38(0.15-0.94)^{*}$ \\
$>9$ hours & 1.00 & 1.00 & 1.00 \\
\hline
\end{tabular}

${ }^{*} p$ value $<0.05$

Unadjusted model consist of bivariate relation between sleeping duration measured with metabolic syndrome. Intermediate model consist of relation between sleeping duration with metabolic syndrome after controlling for screen time (TV time during weekdays. Fully adjusted model consist of relation between sleeping duration with metabolic syndrome after controlling screen time (TV time during weekdays) and physical activity (based on PAQC).

Philippines, $4.8 \%$ [32], in Thailand $7.6 \%$ overweight and 9.0\% obese [33] and in Vietnam $17.8 \%$ and $3.2 \%$ overweight and obese respectively [34], as well as in China, where the prevalence of overweight and obesity combined was documented as $20 \%$ [35]. This study showed that the prevalence of overweight and obesity in Malaysian adolescents is higher compared to other South East Asian countries, mimicking the adult obesity prevalence [4].

The prevalence of metabolic syndrome amongst the 13 years old adolescents in this study was $2.6 \%$, which is lower compared to $4.5 \%$ in the United States [7], and $4.6 \%$ in Vietnam [16], but higher compared to $1.8 \%$ in Korea [15]. Our study also showed a high prevalence of metabolic syndrome among overweight and obese adolescents (10.0\%), whereby 1 in 10 overweight and obese adolescents had metabolic syndrome. However, this is lower than estimates from a community study done by Jalaludin MY et al [17] in Malaysia, and other countries in Europe, Brazil and China [36-40].

Not surprisingly, the individual risk factors of metabolic syndrome (central obesity, high triglyceride, low HDL-cholesterol, high blood pressure and high fasting blood glucose) were found to be higher in overweight and obese group in comparison to the non-obese group. Overweight and obese adolescents with metabolic syndrome were also found to have a much larger waist circumference, higher systolic and diastolic blood pressure, higher triglyceride levels and lower HDLcholesterol levels compared to the non-metabolic syndrome group. However, there was no difference in fasting blood glucose values. Therefore, it would seem prudent to screen overweight and obese adolescents for metabolic syndrome in this population as most of them were asymptomatic for any medical illness such as type 2 diabetes mellitus or hypertension. Intervention programmes aimed at combating metabolic syndrome are necessary to reduce early cardiovascular disease and type 2 diabetes mellitus [41-43].

Previous studies has shown an association between sleeping duration [19-21,44,45], screening time [22,23] and physical activity [24,25] with obesity and other metabolic risk factors. Sleep deprivation may lead to obesity via several mechanisms; including increased sympathetic activity, increased cortisol and ghrelin levels, and decreased leptin levels. These hormonal changes will cause an increase in hunger and appetite 
$[46,47]$. Many studies have shown a U-shaped association between sleep duration and weight gain, whereby both short duration and long duration of sleep leads to weight gain [19-21,44,45]. However, the relationship between sleep duration and metabolic syndrome remains controversial. In adults, several studies have shown a relationship between both short and long sleep duration with metabolic syndrome $[48,49]$. Studies regarding sleep duration and metabolic syndrome in adolescents are few and have not shown any association $[19,50]$. This study contributes to the body of evidence that adolescents who slept between 7 and 9 hours had lower risk to develop metabolic syndrome.

A steady decline in physical activity levels has contributed to an increase in the prevalence of obesity [51]. Decreased physical activity promotes sedentary lifestyle behaviours such as television viewing and playing computer games (screen time). This also has been contributed to the fact that parents prefer their children watching television at home rather than playing outside so they are able to complete their chores and at the same time able to supervise their children [52]. Previous studies have shown a relationship between screen time and metabolic syndrome $[25,53]$. However, we did not find any association between screen time and metabolic syndrome in our study population. This may be due to undereporting, as screening time was assessed as time spent for television viewing but not including time spent for internet browsing and computer games.

The increase in the prevalence of metabolic syndrome poses a public health problem in our country. The development of IDF definition has provided a standard that facilitates comparisons of study results. It helps to identify patients who are at risk of developing atherosclerotic cardiovascular disease and type 2 diabetes mellitus. It also facilitates epidemiological and clinical studies, and this in turn facilitiates prevention and treatment programmes. More research regarding the consequences of metabolic syndrome in adolescents is required. However, at present, the emerging evidence shows that children with metabolic syndrome are at an increased risk of adverse events later in life such as cardiovascular disease and type 2 diabetes mellitus [54].

Routine screening among adolescents is highly recommended to prevent future complications. Many efforts have been made to promote healthy lifestyle in Malaysia to prevent obesity and metabolic syndrome [55]. In 2009, a Cochrane systematic review has identified several potentially useful strategies to treat obesity in children and adolescents [56]. Effective interventions include the incorporation of a healthy diet, reducing sedentary behavior and becoming more physically active $[57,58]$. The Ministry of Health, Malaysia has lauched the National Strategic Plan for Non-Communicable Disease (NSPNCD) in 2010 that focuses on 7 strategies such as prevention and promotion, as well as clinical management of non-communicable diseases [59]. Some intervention programs have been successful, while others have shown moderate success [60,61].

Environment plays an important role in contributing to overweight and obesity problems [55]. For example, food prepared in schools are more energy dense and the snacks provided are mostly fried. This may explain why the prevalence of metabolic syndrome between urban and rural areas are similar, despite the less number of fast foods outlets in the rural areas. Healthier food options should be made available and this needs to be reinforced by the government. Regular physical activity has beneficial effects on metabolic syndrome as it has been shown that physical activity is associated with better insulin sensitivity [62] and a reduction in diastolic blood pressure [63].

As described above, many studies have shown that obesity is linked to physical inactivity, sleeping pattern and sedentary lifestyle behaviours. Hence, these are the factors that should be targeted by any intervention programs for children and adolescents.

\section{Competing interests}

The authors declared no competing interests.

\section{Authors' contributions}

All authors contribute to study design, revising and improving the manuscript; NAS is the principal investigator for MyHEARTS; FAA, MYJ, HAM, TTS and NAS were involved in field work and data collection; FAA, NHMY, TTS and MYJ participated in analysis and interpretation of data; FAA, FH and MYJ drafted the manuscript.

\section{Acknowledgements}

This study was supported by grants from University of Malaya Research Grant (RG299-11HTM) and Vice Chancellor Research Grant (UMQUB3D-2011). The funders had no role in study design, collection, analysis and interpretation of data, writing of manuscript, or decision to submit for publication. We would like to thank all the enumerators who helped us throughout data collection. We are also grateful for the support and guidance provided by our colleagues in the Ministry of Health, the Centre of Population Health, University of Malaya and the Centre of Public Health, Queen's University Belfast.

This article has been published as part of BMC Public Health Volume 14 Supplement 3, 2014: Proceedings of the International Research Symposium on Population Health 2013. The full contents of the supplement are available online at http://www.biomedcentral.com/bmcpublichealth/ supplements/14/S3. Publication charges for this supplement were funded by the University of Malaya.

\section{Authors' details}

${ }^{1}$ Department of Paediatrics, Faculty of Medicine, University Malaya, Malaysia. ${ }^{2}$ Centre for Population Health (CePH), Department of Social and Preventive Medicine, Faculty of Medicine, University Malaya, Malaysia. ${ }^{3}$ Centre for Public Health, Queen's University of Belfast, Belfast, Ireland.

Published: 24 November 2014

\section{References}

1. Cole Tim J, Bellizi Mary C, Flegal Katherine M, Dietz Willian H: Establishing a standard definition for child overweight and obesity worldwide: international survey. BMJ 2000, 320:1240-3.

2. World Health Organization: Obesity: preventing and managing the global epidemic. Report of a WHO consultation: 3-5 Jun 1997; Geneva. 
3. Ismail, Ruzita, Norimah, Poh, Shanita Nik, Mazlan Nik, Roslee Nurunnajiha, Wong, Zakiah Nur, Raduan : Prevalence and Trends of Overweight and Obesity in Two Cross-sectional Studies of Malaysian Children, 2002-2008. Scientific Conference on Obesity 'Obesity and Our Environment' Kuala Lumpur; 2009, 12-13 August.

4. Mohamud Wan Nazaimoon Wan, Musa Kamarul Imran, Khir Amir Sharifuddin Md, Ismail Aziz al-Safi, Ismail Ikram Shah, Kadir Khalid Abdul, Kamaruddin Nor Azmi, Yaacob Nor Azwany, Mustafa Norlaila, Ali Osman Isa Siti Harnida Md, Bebakar Wan Mohamad Wan: Prevalence of overweight and obesity among adult Malaysians: an update. Asia Pac J Clin Nutr 2011, 20(1):35-41.

5. Wee BS, Poh BK, Bulgiba A, Ismail MN, Ruzita AT, Hills AP: Risk of metabolic syndrome among children living in metropolitan Kuala Lumpur: A case control study. BMC Public Health 2011, 11:333

6. Weiss R, Dziura J, Burgert TS, Tamborlane WV, Taksali SE, Yeckel CW, Allen K, Lopes M, Savove M, Morrison J, Sherwin RS, Caprio S: Obesity and the Metabolic Syndrome in Children and Adolescents. The New England Journal of Medicine 2004, 350(23):2362-2374.

7. Ford ES, Li C, Zhao G, Pearson WS, Mokdad AH: Prevalence of the Metabolic Syndrome Among U.S. Adolescents Using the Definition From the International Diabetes Federation. Diabetes Care 2008, 31(3):587-589.

8. Raven GM: Banting Lecture 1988: role of insulin resistance in human diseases. Diabetes 1988, 37(12):1595-1607.

9. Third Report of the National Cholesterol Education Program (NCEP) Expert Panel on Detection, Evaluation and Treatment of High Blood Cholesterol in Adults (Adult Treatment Panel III) Final Report: National Cholesterol Education Program. 2002, National Heart, Lung and Blood Institute, National Institues of Health, NIH Publication No. 02-5215 September

10. Einhorn D, Reaven GM, Cobin RH, Ford E, Ganda OP, Handelsman Y, et al: American College of Endocrinology position statement on the insulin resistance syndrome. Endocrinol Pract 2003, 9:237-252.

11. World Health Organization: Definition, diagnosis and classification of diabetes mellitus and its complications. Geneva, Switzerland; 1999.

12. Alberti KG, Zimmet PZ: Definition, diagnosis and classification of diabetes mellitus and its complications. Part 1: diagnosis and classification of diabetes mellitus provisional report of a WHO consultation. Diabetes Med 1998, 15:539-553.

13. Balkau B, Charles MA: Comment on the provisional report from the WHO consultation. European Group for the Study of Insulin Resistance (EGIR). Diabetes Med 1999, 16:442-443.

14. The IDF Consensus Definition of the Metabolic Syndrome In Children and Adolescents. International Diabetes Federation 2007

15. Park MJ, Boston BA, Oh M, Jee SH: Prevalence and Trends of Metabolic Syndrome Among Korean Adolescents: From the Korean NHANES Survey, 1998-2005. J Pediatr 2009, 155(4):529-534.

16. Hong TK, Trang NH, Dibley MJ: Prevalence of metabolic syndrome and factor analysis of cardiovascular risk clustering among adolescents in Ho Chi Minh City, Vietnam. Preventive Medicine 2012, 55(5):409-411.

17. Jalaludin MY, Abang Abdullah AF, Saiman N, Samingan N, Mohamed Z, Harun F: One in Five Overweight/Obese Adolescents in the Community has Metabolic Syndrome. Ped Diabetes 2012, 13(Suppl 17):106

18. Patel Sanjay R, Hu Frank B: Short sleep duration and weight gain: a systematic review. Obesity 2008, 16(3):643-653.

19. Lee JA, Park HS: Relation between sleep duration, overweight, and metabolic syndrome in Korean adolescents., Nutrition, Metabolism and Cardiovascular Diseases, in press.

20. Cappuccio FP, taggart FM, kandala NM, Currie A, Peile A, Stranges S, Miller MA: Meta-Analysis of Short Sleep Duration and Obesity in Children and Adults. Sleep 2008, 31(5):619-626.

21. Chen MY, Wang EK, Jeng YJ: Adequate sleep among adolescents is positively associated with health status and health-related behaviors. BMC Public Health 2006, 6:59.

22. Hardy LL, Denney-Wilson E, Thrift AP, Okely AD, baur LA: Screen Time and Metabolic Risk Factors Among Adolescents. Arch Pediatr Adolesc Med 2010, 164(7):643-649.

23. Mark $A E$, Janssen I: Relationship between screen time and metabolic syndrome in adolescents. Journal of Public Health 2008, 30(2):153-160.

24. Nyugen TH, Tang HK, Kelly P, van der Ploeg HP, Dibley MJ: Association between physical activity and metabolic syndrome: a cross sectional survey in adolescents in Ho Chi Minh City, Vietnam. BMC Public Health 2010, 10:141.
25. Brage S, Wedderkopp N, Ekelund U, Franks PW, Warenham NJ, Andersen LB, Froberg K: Features of the Metabolic Syndrome Are Associated with Objectively Measured Physical Activity and Fitness in Danish Children. The European Youth Heart Study (EYHS). Diabetes Care 2004, 27:2141-2148.

26. Su TT, Sim PY, Nahar AM, Majid HA, Murray LJ, Cantwell MM, Al-Sadat N, Jalaludin MY: Association between self-reported physical activity and indicators of body composition in Malaysian adolescents. Prev Med 2014, 67:100-105.

27. Abu Hanifah R, Mohamed MNA, Jaafar Z, Al-Sadat N, Jalaludin MY, Majid HA, Murray $\sqcup$, Cantwell MM, Su TT: The Correlates of Body Composition with Heart Rate Recovery after Step Test: An Exploratory Study of Malaysian Adolescents. PloS ONE 2013, 8(12):e82893.

28. Pickering TG, Hall JE, Appel LJ, Falkner BE, Graves J, Hill MN, Jones DW, Kurtz T, Sheps SG, Roccella EJ: Recommendations for Blood Pressure Measurement in Humans and Experimental Animals. Hypertension 2005, 45:142-161.

29. Poh BK, Jannah AN, Chong LK, Ruzita AT, Ismail MN, McCarthy D: Waist circumference percentile curves for Malaysian children and adolescents aged 6.0-16.9 years. International Journal of Pediatric Obesity 2011, 6:229-235

30. Demographic Indicators Malaysia 2012. Department of Statistics, Malaysia 2012, Nov.

31. Ministry of Education Malaysia. Basic School Information January 2012 2012 [http://emisportal.moe.gov.my].

32. Nutritional Status of Filipino Children and Selected Population groups: 2005 Update: Philippine Nutrition Facts \& Figures 2005. Food and Nutrition Research Institute, Department of Sience and Technology; 2008.

33. Jitnarin N, Kosulwat V, Rojroogwasingkul N, Boonpraderm A, Haddock CK, Poston WS: Prevalence of overweight and obesity in Thai population: results of the National Thai Food Consumption Survey. Eat Weight Disord 2011, 16(4):242-249.

34. Nguyen PV, Hong TK, Hoang T, Nguyen DT, Robert AR: High prevalence of overweight among adolescents in Ho Chi Minh City, Vietnam. BMC Public Health 2013, 13:141.

35. Chen F, Wang $Y$, Shan $X$, Cheng $H$, Hou D, Zhao X, Wang T, Zhao D, Mi J: Association between Childhood obesity and metabolic Syndrome: Evidence from a Large Sample of Chinese Children and Adolescents. PloS ONE 2012, 7(10):47380.

36. Bokor S, Frelut ML, Vania A, Hadjiathanasiou CG, Anastasakou M, MaleckaTendera E, Matusik P, Molnár D: Prevalence of metabolic syndrome in European obese children. Int J Pediatr Obes 2008, 3(S2):3-8.

37. Guijarro de Armas MA, Monereo Megías S, Merino Viveros M, Iglesias Bolaños P, Vega Piñero B: Prevalence of metabolic syndrome in a population of obese children and adolescents. Endocrinología y Nutrición 2012, 59(3):155-159.

38. Lafortuna CL, Adorni F, Agosti F, De Col A, Sievert K, Siegfried W, Sartorio A Prevalence of the metabolic syndrome among extremely obese adolescents in Italy and Germany. Diabetes Research and Clinical Practice 2010, 88(1):14-21.

39. Sangun ö, Dündar B, Köşker M, Pirgon ö, Dündar N: Prevalence of metabolic syndrome in obese children and adolescents using three different criteria and evaluation of risk factors. J Clin res Pediatr Endocrinol 2011, 3(2):70-76

40. Wang Q, Yin J, Xu L, Cheng H, Zhao X, Xiang H, Li M: Prevalence of metabolic syndrome in a cohort of Chinese schooldchildren: a comparison of two definitions and assessment of adipokines as components by factor analysis. BMC Public Health 2013, 13:249.

41. Ballantyne CM, Hoogeveen RC, McNeill AM, Heiss G, Schmidt MI, Duncan BB, Pankow JS: Metabolic syndrome risk for cardiovascular disease and diabetes in the ARIC study. International Journal of Obesity 2008, 32(Suppl 2):21-24.

42. Mottillo S, Filion KB, Genest J, Joseph L, Pilote L, Poirier P, Rinfret S, Schiffrin EL, Eisenberg MJ: The Metabolic Syndrome and Cardiovascular Risk: A Systematic Review and Meta-Analysis. Journal of the American College of Cardiology 2010, 56(14):1113-1132.

43. Wilson PW, D'Agostino RB, Parise H, Sullivan L, Meigs JB: Metabolic Syndrome as a Precursor of Cardiovascular Disease and Type 2 Diabetes mellitus. Circulation 2005, 112:3066-3072.

44. Patel SR, Hu FB: Short sleep duration and weight gain: a systematic review. Obesity 2008, 16(3):643-653. 
45. Bawazeer NM, Al-Daghri NM, Valsamakis G, Al-Rubeaan KA, Sabico SL, Huang TT, Mastorakos GP, Kumar S: Sleep duration and quality associated with obesity among Arab children. Obesity 2009, 17(12):2251-2253.

46. Van Cauter E, Holmback U, Knutson K, Leproult R, Miller A, Nedeltcheva A, Pannain S, Penev $P$, Tasali E, Spiegel K: Impact on sleep and sleep loss on neuroendocrine and metabolic function. Horm Res 2007, 67(Suppl 1):2-9.

47. Taheri S, Lin L, Austin D, Young T, Mignot E: Short sleep duration is associated with reduced leptin, elevated ghrelin, and increased body mass index. PloS Med 2004, 1(3):62.

48. Arora T, Jiang CQ, Thomas GN, Lam KB, Zhang WS, Cheng KK, Lam TH, Taheri S: Self-reported long total sleep duration is associated with metabolic syndrome: the Guangzhou Biobank Cohort Study. Diabetes Care 2011, 34:2317-2319.

49. Choi KM, Lee JS, Park HS, Baik SH, Choi DS, Kim SM: Relationship between sleep duration and the metabolic syndrome: Korean National Health and Nutrition Survey 2001. Int J Obes 2008, 32:1091-1097.

50. Sung V, Beebee DW, Vandyke R, Fenchel MC, Crimmins NA, Kirk S, Hiscock H, Amin R: Does sleep duration predict metabolic risk in obese adolescents attending tertiary services? A cross-sectional study. Sleep 2011, 34(7):891-898.

51. Denghan M, Akhtar-Danesh N, Merchant AT: Childhood obesity, prevalence and prevention. Nutr J 2005, 4(1):24.

52. Gordon-Larsen P, Griffiths P, Bentley ME, Ward DS, Kelsey K, Shields K, Ammerman $A$ : Barriers to physical activity: qualitative data on caregiverdaughter perceptions and practices. Am J Prev Med 2004, 27:218-223.

53. Shaalan IQ, AlHarmoudi FA, AlMarzooqi SA, AlNaqbi ZM, AlMedhani RA, AlMansouri Rl, Shah SM: Relation between screen time and metabolic syndrome among Emirati adolescents. Arch Dis Child 2012, 97:128-129.

54. Cruz ML, Goran MI: The Metabolic Syndrome in Children and Adolescents. Current Diabetes Reports 2004, 4(1):53-62.

55. Sidik SM, Ahmad R: Childhood Obesity: contributing factors, consequences and intervention. Malaysian Journal of Nutrition 2004, 10(1):13-22.

56. Oude Luttikhuis $H$, Baur L, Jansen $H$, Shrewsbury VA, O'Malley C, Stolk RP, Summerbell CD: Interventions for treating obesity in children. Cochrane Database Syst Rev 2009, 21(1):CD001872.

57. Sargent GM, Pilotto LS, Baur LA: Components of primary care interventions to treat childhood overweight and obesity: a systematic review of effect. Obes Rev 2011, 12(5):219-235.

58. Baker JL, Farpour-Lambert NJ, Nowicka P, Pietrobelli A, Weiss R: Evaluation of the overweight/obese child. Practical tips for the primary health care provider: recmmendations from the Childhood Obesity Task Force of the European Association for the Study of Obesity. Obes Facts 2010, 3:131-137.

59. National Strategic Plan for Non-Communicable Disease: Medium Term Strategic Plan to Further Strengthen the Cardiovascular Diseases and Diabetes Prevention and Control Program in Malaysia (2010-2014) Ministry of Health Malaysia 2010.[http://www.moh.gov.my].

60. Kahn EB, Ramsey LT, Brownson RC, Health GW, Howze EH, Powell KE, Stone EJ, Rajab MWm, Corso P: The Effectiveness of Interventions to Increase Physical Activity. A Systematic Review. Am J Prev Med 2002, 22(Suppl 4):73-107.

61. Waters E, de Silva-Sanigorski A, Hall BJ, Brown T, Campbell KJ, Gao Y, Armstrong R, Prosser L, Summerbell CD: Interventions for preventing obesity in children. Cochrane Database of Systematic Reviews 2011, 12: CD001871.

62. Schmitz KH, Jacobs DR Jr, Hong CP, Steinberger J, Moran A, Sinaiko AR: Association of physical activity with insulin sensitivity in children. Int J obes 2002, 26(10):1310-1316.

63. Kang Hs, Gutin B, Barbeau P, Owens S, Lemmon CR, Allison J, Litaker MS, Le NA: Physical training improves insulin resistance syndrome markers in obese adolescents. Med Sci Sports Exerc 2002, 34(12):1920-1927.

doi:10.1186/1471-2458-14-S3-S7

Cite this article as: Fadzlina et al:: Metabolic syndrome among 13 year old adolescents: prevalence and risk factors. BMC Public Health 2014 14(Suppl 3):S7.

\section{Submit your next manuscript to BioMed Central and take full advantage of:}

- Convenient online submission

- Thorough peer review

- No space constraints or color figure charges

- Immediate publication on acceptance

- Inclusion in PubMed, CAS, Scopus and Google Scholar

- Research which is freely available for redistribution 